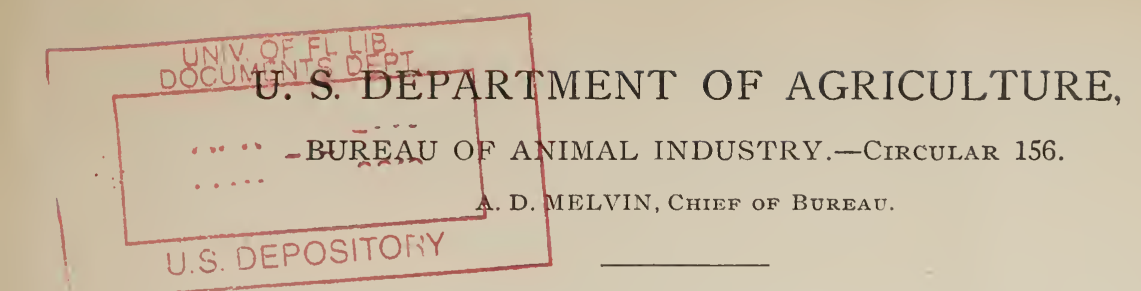

\title{
CHRONIC BACTERIAL DYSENTERY OF CATTLE. ${ }^{a}$
}

\author{
By JoHn R. MOHLER, V. M. D., \\ Chief of the Pathological Division.
}

Chronic bacterial dysentery is a chronic infectious disease of bovines caused by an acid-fast bacillus simulating the tubercle bacillus. It is characterized by marked diarrhea, anemia, and emaciation, terminating in death. It has also been termed by various European investigators Johne's disease, chronic bacterial enteritis, chronic hypertrophic enteritis, and chronic bovine pseudo-tuberculosis enteritis.

Recently this disease has been observed in the United States for the first time by Pearson in Pennsylvania cattle, and later by Beebe in Minnesota and by Mohler in Virginia cattle and in an imported heifer from the Island of Jersey at the Athenia, N. J., quarantine station of the Bureau of Animal Industry. Pearson has proposed the name "chronic bacterial dysentery" for this affection.

The disease was first studied in 1895 by Johne and Frothingham in Dresden, but they were inclined to attribute the cause of the peculiar lesions of enteritis which they observed to the avian tubercle bacillus. In 1904 Markus reported the disease in Holland, and subsequently it was observed in Belgium, Switzerland, Denmark, and Great Britain.

\section{CAUSE.}

The bacillus which has been invariably demonstrated in the intestinal lesions and mesenteric lymph glands in this disease is a rod about 2 to 3 microns long and 0.5 micron wide. It stains more or less irregularly, like the tubercle bacillus, and, moreover, the similarity goes farther in that the organism is also strongly acid-fast, which facts led Johne and Frothingham to surmise that the disease was caused by avian tubercle bacilli. However, it has now been plainly demonstrated that the bacillus of chronic bacterial dysentery is readily distinguished from those organisms, for while it resembles the tubercle bacillus in form and staining qualities, no one has suc-

${ }^{a}$ Reprinted from the Twenty-fifth Annual Report of the Bureau of Animal Industry (1908).

27640 -Cir. $156-10$ 
ceeded in growing it in culture media or in reproducing the disease by injecting experiment animals.

\section{SYMPTOMS.}

Probably the first symptom noticed is that the animal is losing condition despite the fact that its appetite is good and the feed nourishing. This is soon followed by a diarrhea which is moderate at first, but soon becomes excessive and may be either irregular or persistent, the feces being of the consistency of molasses and passed frequently. In the meantime the hair becomes dry and harsh and the animal falls off considerably in weight. (See fig. 1.) The temperature, however, remains about normal. The appetite does not seem to be greatly

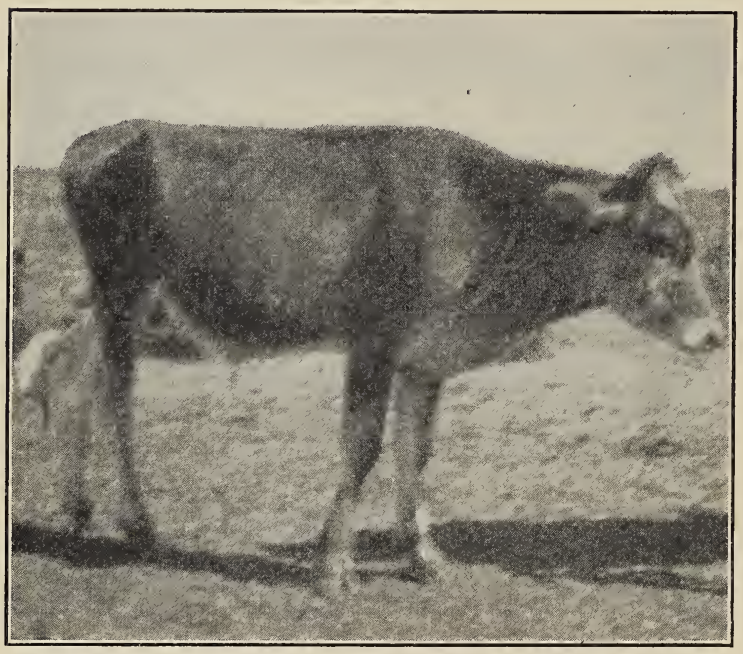

FIG. 1.-Steer affected with chronic bacterial dysentery. impaired until the last few. weeks of life, but nevertheless emaciation continues, the animal becomes more and more anemic, great $\mathrm{muscular}$ weakness and exhaustion are manifested, and death follows, apparently as the result of the persistent diarrhea and great emaciation. The disease may continue for four or five weeks or may last for a ycar or even longer before death intervenes.

LESIONS.

The lesions observed on post-mortem are remarkably slight and out of all proportion to the severity of the symptoms manifested. The disease appears to start in the small intestines, especially in the lower portion, where the lesions are usually the most marked, but it also involves the large intestines, including the rectum. The mucous membrane may alone be affected, although usually in the long-standing cases the submucosa is also invaded, and the entire intestinal wall is then much thicker than normal and the tissue infiltrated with an inflammatory exudate. The mucous membrane or inside lining membrane is markedly wrinkled or corrugated, showing large coarse folds with more or less reddening or hemorrhagic patches or spots on the summits of the ridges, especially noticeable in the large intestines. 
The mesenteric lymph glands are usually somewhat enlarged and appear watery on section. The other organs do not appear to be affected except from the anemia present in the later stages of the disease.

\section{DIFFERENTIAL DIAGNOSIS.}

The principal disease with which bacterial dysentery may be confused is tuberculosis, but the application of the tuberculin test will readily diagnose the latter disease, while no reaction will be noted in case the injected animal is suffering with only the former affection. The disease may also be mistaken for the parasitic affections resulting from stomach worms (verminous gastritis) and intestinal parasites, especially uncinariasis, in which case a microscopic examination of the feces is necessary in order to establish definitely the diagnosis.

\section{TREATIIENT.}

As with all other forms of infectious disease, it is advisable to separate immediately the diseased and suspected cattle from the healthy animals. The feces passed by the former should be placed on cultivated soil where healthy cattle would not be exposed to them, as the bacilli producing the disease are readily found in such manure. The stalls, stables, and barnyards should also be thoroughly disinfected, special attention being given to those places which have been soiled by feces.

The administration of medicines has thus far been quite unsatisfactory, although treatment should be directed toward disinfecting the intestines with intestinal antiseptics, such as creolin in 2-teaspoonful doses given twice daily. Salol, turpentine, or subnitrate of bismuth in a starch or wheat-flour gruel may also give temporary relief, but the diarrhea is likely to reappear and cause the death of the animal. In all cases the food must be carefully selected to assure good quality, and should consist preferably of nutritious dry feed.

[Cir. 156] 
UNIVERSITY OF FLORIDA

31262089293764 